\title{
LEITURA LITERÁRIA: REFLEXÕES SOBRE OS DESAFIOS NA ATUAÇÃO DE DOCENTES DE ESCOLAS PÚBLICAS DIANTE DAS TECNOLOGIAS DIGITAIS ${ }^{1}$
}

\author{
LITERARY READING: REFLECTIONS ON THE CHALLENGES IN THE \\ PERFORMANCE OF PUBLIC SCHOOL TEACHERS IN DIGITAL \\ TECHNOLOGIES
}

\author{
Patrícia VERTUAN ${ }^{2}$ \\ Universidade do Estado de Mato Grosso \\ UNEMAT/ Campus Sinop \\ Saionara Mazzochin TORRES ${ }^{3}$ \\ Universidade do Estado de Mato Grosso \\ UNEMAT/ Campus Sinop \\ Albina Pereira de Pinho SILVA ${ }^{4}$ \\ Universidade do Estado de Mato Grosso \\ UNEMAT/ Campus Sinop
}

\begin{abstract}
RESUMO: Este artigo tem por objetivo apresentar os resultados de uma pesquisa realizada com professoras de Língua Portuguesa do Ensino Fundamental ( $6^{\circ}$ ao $9^{\circ}$ ano) e Ensino Médio, das redes estadual e municipal de ensino em Marcelândia-MT, acerca da leitura literária em sala de aula. Ao mesmo tempo, pretendemos discutir os desafios e perspectivas diante das novas tecnologias digitais que se fazem presentes na rotina dos alunos. Dadas as consideráveis mudanças socioculturais, não há como dissociar a educação dessas tecnologias. Elas estão presentes em todos os segmentos sociais, o que exige da escola um reposicionamento no sentido de integrá-las, sob a perspectiva contextualizada no processo de ensino e aprendizagem. Para a coleta de dados utilizamos a técnica de questionário (GIL, 2008), desenvolvida com suporte do aplicativo Google Forms ${ }^{5}$. Tomamos como enfoque teórico a BNCC ${ }^{6}$ (2017) as OC 7 (2012), o letramento literário (COSSON, 2012) e o letramento digital (COSCARELLI, 2012). O conjunto de dados da pesquisa aponta que ainda existe a concepção de ensino de literatura limitado à leitura de livros impressos, ou seja, por mais que a escola já disponibilize recursos e tecnologias acessíveis aos estudantes e professores, o uso desses recursos não é predominante ou relevante. No entanto, entre a maior parte das colaboradoras da pesquisa, há uma percepção das tecnologias como aliadas da leitura literária desde que utilizadas de modo consciente e situado no contexto de aprendizagem.
\end{abstract}

Palavras-chave: Leitura literária, Atuação docente, Letramento digital.

ABSTRACT: This article aims to present the results of a research carried out with teachers of Portuguese Language of Elementary School (6th to 9th grade) and High School, of the state and municipal teaching networks in Marcelândia-MT, about literary reading in the classroom. At the same time, we intend to discuss the challenges and perspectives of the new digital technologies that are present in the routine of students. Given the considerable sociocultural changes, there is no way to decouple education and digital

\footnotetext{
${ }^{1}$ Este trabalho resulta de uma atividade desenvolvida na disciplina de Leitura do Texto Literário, do Mestrado Profissional em Letras - PROFLETRAS - Campus Sinop, no segundo semestre/ 2018.

${ }^{2}$ Discente do Mestrado Profissional em Letras - PROFLETRAS -, da Universidade do Estado de Mato Grosso (UNEMAT), Campus Sinop.

${ }^{3}$ Discente do Mestrado Profissional em Letras - PROFLETRAS -, da Universidade do Estado de Mato Grosso (UNEMAT), Campus Sinop.

${ }^{4}$ Doutora em Educação (UFRGS), Docente do PROFLETRAS, da Universidade do Estado de Mato Grosso (UNEMAT), Campus Sinop.

${ }^{5}$ Aplicativo gratuito para elaboração de questionários online.

${ }^{6}$ Base Nacional Comum Curricular.

${ }^{7}$ Orientações Curriculares do Estado de Mato Grosso.
} 
technologies. They are present in all social segments, which require a repositioning of the school in the sense of integrating them, in relation to the contextualized perspective in the teaching and learning process. For the data collection, we used the questionnaire technique (GIL, 2008), developed with support of the Google Forms application. We take as a theoretical approach the BNCC (2017), the OC (2012), literary literacy (COSSON, 2012) and digital literacy (COSCARELLI, 2012). The data set of the research indicates that there is still the concept of literature teaching limited to reading of printed books, that is, even though the school already provides resources and technologies accessible resources and technologies to students and teachers, their use is not predominant or relevant. However, among most of the research contributors, there is a perception of technologies as allied of literary reading, since they are used consciously and situated in the context of learning.

Key words: Literary reading, Teaching experience, Digital literacy.

\section{Introdução}

Este artigo trata de uma pesquisa sobre o uso das tecnologias digitais ${ }^{8}$, como aliadas no estudo da Língua Portuguesa e de Literatura, no Ensino Fundamental, tendo como suporte um questionário quanto ao uso dessa ferramenta, aplicado a professores das redes estadual e municipal, que atuam no município de Marcelândia/MT.

Ao observar as mudanças motivadas principalmente pelas tecnologias digitais, visto que essas promovem consideráveis modificações nas atividades humanas, com extrema rapidez, é que se faz necessário repensar a função social da educação de forma contínua e compreender que a sociedade contemporânea sofre a influência dessas tecnologias, modificando-se a cada clique.

Dadas as consideráveis mudanças socioculturais resultantes do surgimento de novas tecnologias, não há como dissociar a educação e as tecnologias digitais, pois essas estão presentes em todos os segmentos da sociedade fato que exige da escola um reposicionamento no sentido de integrá-las ao processo de ensino/ aprendizagem. Quanto à leitura literária, a tecnologia digital já atingiu essa esfera e está sendo incorporada às suas metodologias. Não se trata de mudar radicalmente o que está colocado, ou seja, os bons resultados que o ensino tradicional consolidou. Trata-se de acrescentar o novo ao já existente e, assim, atingir os objetivos propostos, principalmente, no que tange a acompanhar as mudanças sociais e intelectuais que acontecem de forma natural, em consequência de pesquisas e aprimoramentos decorrentes da globalização e da rápida disseminação de informações. Nessa

\footnotetext{
${ }^{8}$ Tecnologia digital é um conjunto de tecnologias que permite, principalmente, a transformação de qualquer linguagem ou dado em números, isto é, em zeros e uns ( 0 e 1). Uma imagem, um som, um texto, ou a convergência de todos eles, que aparecem para nós na forma final da tela de um dispositivo digital na linguagem que conhecemos (imagem fixa ou em movimento, som, texto verbal), são traduzidos em números, que são lidos por dispositivos variados, que podemos chamar, genericamente, de computadores. Disponível em: http://www.ceale.fae.ufmg.br/app/webroot/glossarioceale/verbetes/tecnologia-digital Acesso em: 01 maio 2019.
} 
perspectiva, as Orientações Curriculares do Estado de Mato Grosso (OC) preconizam que:

\begin{abstract}
"não se trata de substituição de tecnologias ou acréscimo de uma nova tecnologia. Trata-se de levar em conta as mudanças provocadas pela informática na sociedade, na cultura, na linguagem, nas formas de pensar e construir conhecimento. É preciso que a escola entenda essas mudanças e procure entrar em sintonia com o mundo em que o aluno está imerso, tornando-se lugar de debate, de discussão, de interpretação da crescente quantidade de informações, constantemente atualizadas, de modo que ele possa atribuir sentidos, conhecimentos, processo que depende das interações que estabelece com os outros." (MATO GROSSO, 2012, p. 66)
\end{abstract}

A importância em atribuir sentido ao que será trabalhado é um fator decisivo para que as atividades realizadas alcancem os resultados esperados. Para isso, é necessário levar em consideração a idade dos estudantes, a realidade na qual estão inseridos e, acima de tudo, dialogar na perspectiva de um processo democrático porém, não permissivo -, para que as obras literárias a serem exploradas pela turma estejam de acordo com suas reais necessidades.

Entendemos que o trabalho com a leitura literária, na escola, é primordial para o desenvolvimento e aprendizagem do estudante. Também é necessária uma contínua discussão a respeito da obra a ser estudada, pois, além de aprimorar o conhecimento e letramento literário dos estudantes, promoverá situações de aprendizagem que lhes favorecem, nos processos de humanização e reflexão. De acordo com Cosson (2012, p. $17)$,

\footnotetext{
"a literatura nos diz o que somos e nos incentiva a desejar e a expressar o mundo por nós mesmos. E isso se dá porque a literatura é uma experiência a ser realizada. É mais que um conhecimento a ser reelaborado, ela é a incorporação do outro em mim sem renúncia da minha própria identidade. No exercício da literatura, podemos ser outros, podemos viver como os outros, podemos romper os limites do corpo e do espaço de nossa experiência e, ainda assim, sermos nós mesmos. É por isso que interiorizamos com mais intensidade as verdades dadas pela poesia e pela ficção."
}

Dada a reflexão, conclui-se que há várias possibilidades de explorar a leitura por meio de material impresso e também digital, uma vez que as tecnologias digitais estão acessíveis, são leves, fáceis de serem transportadas, editadas, reescritas e contextualizadas. Não há como se abster da responsabilidade, enquanto educadores, de integrá-las às práticas como suporte pedagógico, que pode contribuir e, por conseguinte, potencializar o ensino da literatura na escola. 


\title{
Literatura e o desafio de formação de leitores
}

Sabemos que boa parte dos estudantes não tem motivação nem proficiência em leitura literária. Em contrapartida, a leitura tem um vasto poder de encantamento, que precisa ser cultivado ou, em alguns casos, despertado nos estudantes, principalmente, naqueles que leem tão somente quando são cobrados.

Embora saibamos que há crianças que foram motivadas a ler, ainda na primeira infância, principalmente quando os pais também têm o hábito da leitura, apresentando chances maiores de se tornarem bons leitores, é necessário buscar despertar e cultivar esse hábito. Não importa que idade tenha o estudante, pois todos merecem as mesmas oportunidades, independentemente do acesso a que tiveram a esses materiais ou quão favorável foi o ensino realizado em anos iniciais. Como as OC descrevem:

\begin{abstract}
A literatura apesar de não pretender um objetivo específico ou compromisso com quer que seja, a não ser consigo mesma e com seu desejo de desvelar o mundo endurecido, enquanto arte se posta como meio de educação da sensibilidade; como meio de atingir um conhecimento tão importante quanto o científico, embora se faça por outros caminhos; como meio de pôr em questão (fazendo-se crítica) o que parece ser ocorrência/decorrência natural; como meio de transcender o simplesmente dado, mediante o gozo da liberdade que só a fruição estética permite; como meio de acesso a um conhecimento que objetivamente não se pode mensurar como meio, sobretudo, de humanização do homem coisificado: esses são alguns papéis reservados à arte, de cuja apropriação todos têm direito. (MATO GROSSO, 2012, p. 53).
\end{abstract}

O trabalho pedagógico com leitura em sala de aula é uma atividade extremamente importante na formação de leitores, visto que grande parte da população não tem acesso a livros senão no ambiente escolar. A leitura na escola pode ser feita de várias formas, entre elas, leitura em voz alta, leitura compartilhada, leitura feita pelo professor, e dessa forma é possível compartilhar também as diversas interpretações, pois cada estudante irá compreender de acordo com a realidade em que está inserido e pelas suas experiências de vida.

Ler e reler um texto é uma estratégia que contribui na interpretação do que está sendo lido, além de facilitar uma análise mais completa, uma reflexão que envolve além da compreensão, curiosidades sobre a época, o contexto, para quê e por quem foi escrito.

Ainda não se pode deixar de considerar o quanto é possível e relevante que o professor promova a leitura literária, por meio de ferramentas digitais, visto que estão cada vez mais ganhando espaço na sociedade atual, já que os estudantes estão 
habituados a manusear estes aparelhos, sem contar que são atrativos e podem tornar a aula mais interessante para essa geração de nativos digitais ${ }^{9}$.

Lajolo (2001, p. 120) assevera que:

\begin{abstract}
“ o computador contribui também para os estudos literários, já que a teoria do hipertexto fortalece uma concepção de literatura que a entende como um tipo de discurso cuja leitura supõe um leitor capacitado a recuperar de forma consciente as formas de intertextualidade - menções a outros textos presentes em cada texto que ele lê. Nesse sentido, a leitura literária exige familiaridade do leitor com o repertório de textos com que se articula cada um dos textos que ele lê, repertório em constante expansão, mais e mais aberto, quanto mais o leitor lê.
\end{abstract}

Temos conhecimento de que, por muito tempo, os livros didáticos, foram a única ferramenta utilizada em sala, e o texto, por muitas vezes, foi usado como pretexto para o ensino da gramática. Porém, essa realidade não convence mais os atores do processo, o desafio está posto às escolas: utilizar a tecnologia digital não é mais uma discussão se deve ou não acontecer, já aconteceu. O objetivo principal da discussão está em como fazer para que os resultados sejam exitosos. É válido ressaltar que a participação e imersão na cultura digital requer competência semiótica do usuário, por exigir e permitir que ele tenha e/ou adquira habilidades em ler não somente o texto verbal, mas também as imagens, as cores e tudo o quanto estiver disponível, no sentido de inferir significados e ampliar a compreensão e competência leitora.

Para isso, é necessário explorar a multimodalidade presente nos textos digitais, pensar e repensar cada detalhe, com vistas a um alcance maior da leitura, a qual exige reflexão. De acordo com Santaella (2007, p. 80) exigem "vigilância, receptividade, escolha, colaboração, controle, desvios, reenquadramentos em estados de imprevisibilidade ou de acasos, desordens, adaptabilidades".

Para Coscarelli (2011), é importante lembrar que o computador não tomará o lugar de ninguém. Ele é apenas uma máquina que não funciona sozinha e para ser operacionalizada, necessita de pessoas com qualificação para tal e que estrategicamente formulem metodologias para surtir efeito, caso contrário, não fará diferença, visto que

\footnotetext{
${ }^{9} \mathrm{O}$ termo nativo digital foi criado pelo norte-americano Marc Prensky e refere-se àquele que nasceu e cresceu com as tecnologias digitais presentes em sua vivência.
} 
pode ser usado para decorar regras, tabuadas, e outros conteúdos tradicionais cujo processo de aprendizagem ocorria sem o uso da tecnologia digital.

O documento elaborado para a Base Nacional Comum Curricular (BNCC) aponta para as mudanças decorrentes das diversidades presentes na sociedade contemporânea, com a conectividade e acesso às interfaces digitais, que resultaram em multissemioses que exigem novos letramentos ou multiletramentos para a leitura crítica de mundo e atuação ativa na sociedade. Essas mudanças tornam cada vez mais evidente a necessidade de as instituições escolares, bem como os profissionais da educação se adequarem e reorganizarem pedagogicamente, pois estão diante de uma nova realidade e, com ela, cada vez maiores desafios a serem superados.

\section{Método da pesquisa}

Este estudo fundamenta-se nos princípios teórico-metodológicos do método de pesquisa qualitativa. Este método de investigação privilegia dados descritivos, por isso o foco não está em quantificar, mas em compreender os fenômenos sociais e culturais e seus dimensionamentos nos contextos escolares.

Para a geração de dados da pesquisa utilizamos um de questionário, que Gil (2008) define como a técnica de investigação em que se submete um conjunto de questões a pessoas com o intuito de obter informações sobre assuntos diversos:

\footnotetext{
Construir um questionário consiste basicamente em traduzir objetivos da pesquisa em questões específicas. As respostas a essas questões é que irão proporcionar os dados requeridos para descrever as características da população pesquisada ou testar as hipóteses que foram construídas durante o planejamento da pesquisa. (GIL, 2008, p. 121)
}

A pesquisa teve como foco averiguar o quanto as tecnologias de informação e comunicação e as tecnologias digitais têm influenciado a atuação dos docentes em relação à leitura literária. Foram considerados fatores como formação inicial e continuada, idade, recursos disponíveis na escola em que atuam, entre outros relevantes para a análise dos dados qualitativos da pesquisa.

O processo de estruturação da pesquisa compôs-se das seguintes etapas: escolha dos temas, aporte teórico, construção do questionário, coleta e análise de dados. A formulação do questionário deu-se mediante a utilização do aplicativo Google Forms ${ }^{10}$.

\footnotetext{
${ }^{10}$ Aplicativo gratuito para elaboração de questionários online.
} 
Em seguida, o questionário foi encaminhado por um $\operatorname{link}^{11}$ pelo aplicativo de mensagens Whatsapp. A mensagem com o link foi acompanhada de um convite para participar da pesquisa e uma explicação sobre a origem e o objetivo da pesquisa, bem como identificação das pesquisadoras responsáveis.

As doze questões, apresentadas a seguir, das quais sete objetivas e cinco subjetivas, foram elaboradas com a preocupação ética em preservar a verdadeira identidade dos participantes.

1. Indique sua faixa etária.

2. Qual é sua formação acadêmica?

3. Indique seu nível de escolaridade.

4. Há quanto tempo leciona Língua Portuguesa?

5. Em quantas turmas leciona Língua Portuguesa atualmente?

6. Qual sua carga horária total de trabalho semanal?

7. Assinale o(s) recurso(s) digitais que a escola disponibiliza.

8. Dos recursos digitais abaixo, indique os que você utiliza em suas aulas.

9. Já participou de formação ou curso voltado para o uso de tecnologias educacionais digitais? Justifique.

10. Em sua opinião, qual a influência das mídias digitais quanto ao incentivo à leitura literária?

11. Para você, quais são as maiores dificuldades em relação à leitura literária na escola?

12. Além do Youtube e os E-books (livros eletrônicos), cite aplicativos ou programas que você conheça, utiliza ou poderia utilizar em aulas de leitura.

O convite para responder o questionário estendeu-se às doze professoras que, em 2018, atuaram em sala de aula de Língua Portuguesa no Ensino Fundamental (6 $6^{\circ}$ ao $9^{\circ}$ ano) e Ensino Médio, nas escolas das Redes Estadual e Municipal, na Zona Urbana, em Marcelândia, município localizado na região Norte do estado de Mato Grosso.

\footnotetext{
11 “O link pode ser entendido como uma área dentro de um texto que é a fonte ou o destino da ação de clicar. Ou seja, clica-se num link para abrir outro link. O link pode ser todo o conteúdo (por exemplo, os textos/imagens tipo pop up) ou parte dele." Vide: GOMES, Luiz Fernando. Hipertexto no cotidiano escolar. 1. ed. São Paulo: Cortez, 2011. (p. 26)
} 


\section{Apresentação e análise de dados}

Das doze professoras ${ }^{12}$ convidadas, somente oito participaram. As primeiras questões objetivas forneceram dados para a escrita do perfil das participantes. Para tanto, coletamos informações referentes à idade, tempo em que leciona Língua Portuguesa, formação acadêmica e nível de escolaridade.

Conforme o gráfico (figura 1), todas as docentes se encontram na faixa etária acima de 30 anos. As que têm entre 41 e 50 anos correspondem a 25\%, entre 31 e 40 são $37,5 \%$ e algumas já passaram dos 50 anos (37,5\%).

Figura 1: Gráfico indicativo de faixa etária

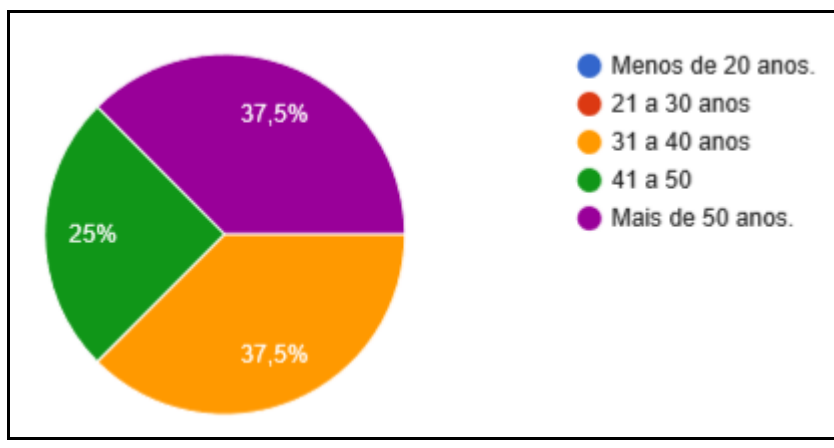

Fonte: Acervo das pesquisadoras

Quanto ao nível de escolaridade, a maior parte das pesquisadas possui Especialização com pós-graduação completa, enquanto as demais possuem graduação ou pós-graduação incompleta (figura 2). Todas indicaram ter graduação em Letras. Este é um dado importante, pois até poucas décadas, no Estado de Mato Grosso, ainda não havia profissionais habilitados, de modo que nem sempre o profissional que assumia as aulas de Língua Portuguesa tinha formação na área para o exercício dessa função.

\footnotetext{
${ }^{12}$ Empregamos o substantivo no gênero feminino, pois, no momento da realização da pesquisa, havia somente mulheres atuando em sala de aula de Língua Portuguesa nas referidas séries/etapas de ensino que delimitaram o foco do estudo.
} 
Figura 2: Gráfico indicativo de nível de escolaridade

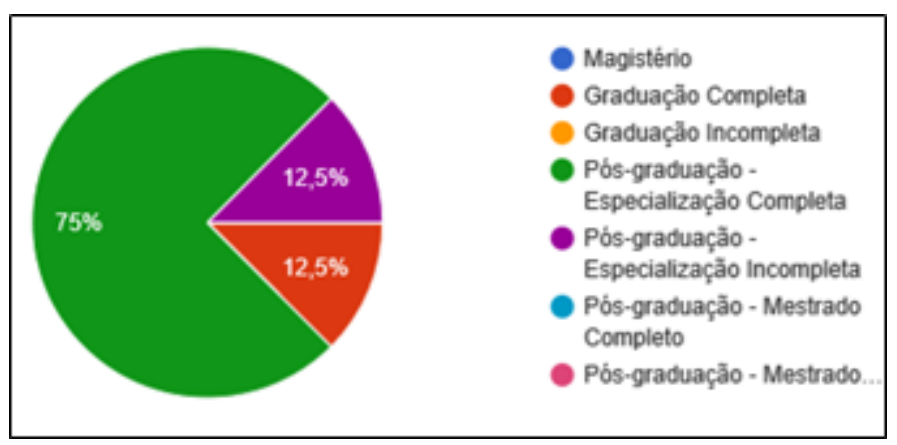

Fonte: Acervo das pesquisadoras.

Em relação à jornada de trabalho semanal, as respostas indicaram que 50\% das professoras cumprem jornada de 40 horas semanais (figura 4). Entre as respondentes, havia profissionais com pouco tempo de experiência em sala de aula de Língua Portuguesa, conforme demonstra o gráfico (figura 3) com menos de 5 anos, 37,5\% tinham entre 11 e 20 anos $(37,5 \%)$ e a menor parte possui de 6 a 10 anos de carreira, o que corresponde a $25 \%$.

Figura 3: Gráfico indicativo de tempo em que leciona Língua Portuguesa

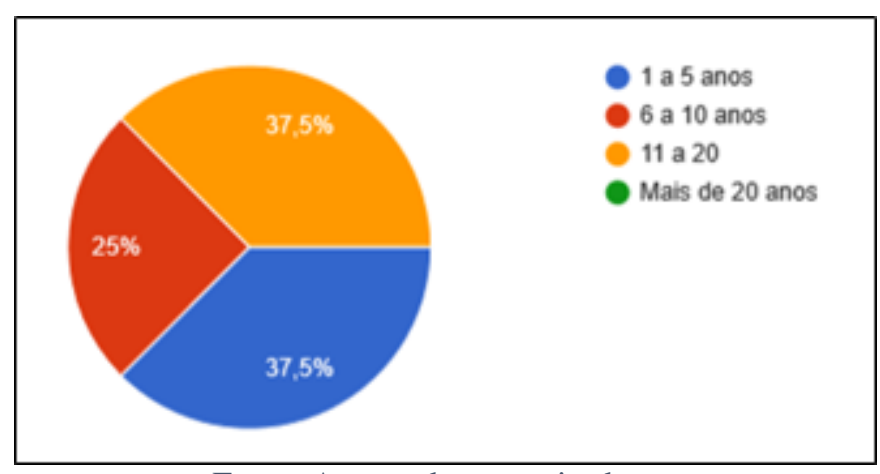

Fonte: Acervo das pesquisadoras. 
Figura 4: Gráfico indicativo de carga horária total de trabalho semanal.

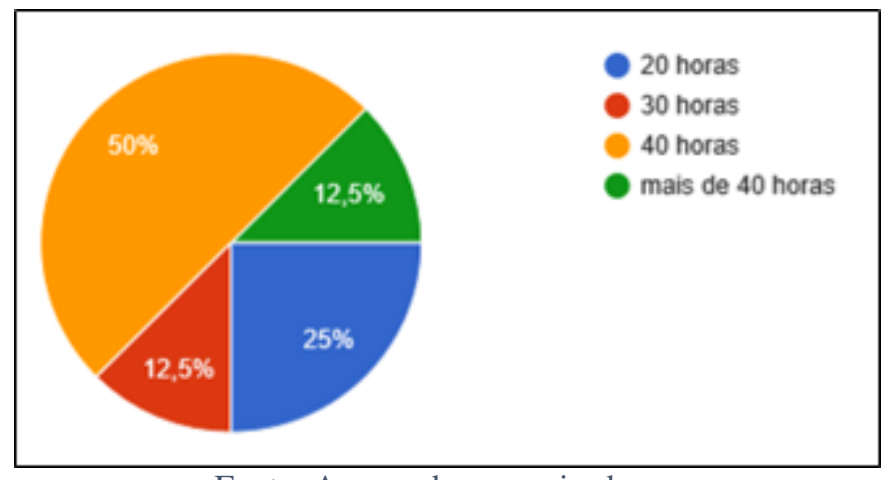

Fonte: Acervo das pesquisadoras.

Uma das questões refere-se aos recursos tecnológicos disponibilizados pelas escolas em que as professoras atuam. Entre as alternativas sugeridas, o único item presente em todas as escolas é o laboratório de informática, porém o mais utilizado, segundo a pesquisa, é a Internet sem fio, conforme mostra o gráfico (figura 5).

Figura 5: Gráfico indicativo de recursos utilizados pela professora.

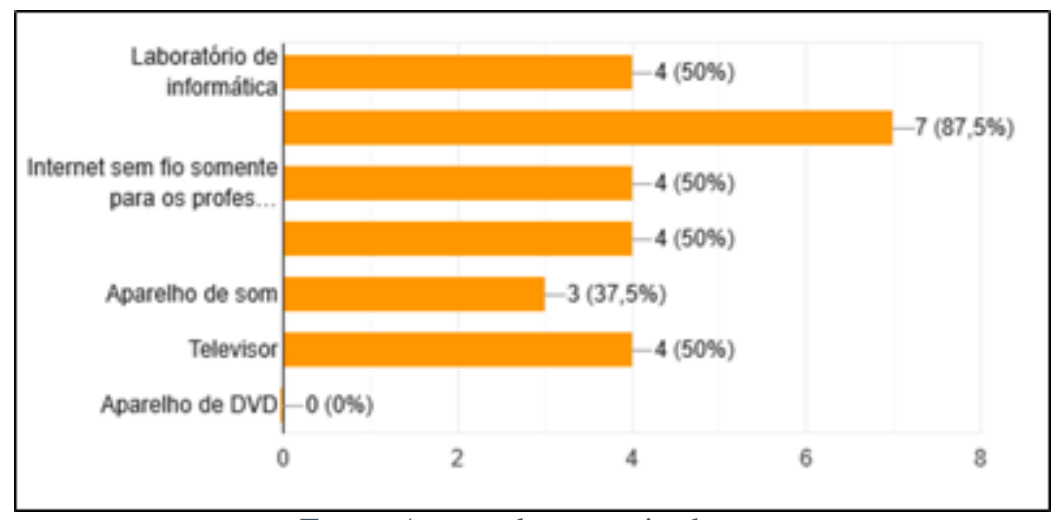

Fonte: Acervo das pesquisadoras.

Ao serem questionadas se já participaram de formação ou curso voltado para o uso de tecnologias educacionais digitais, quatro afirmaram nunca terem participado e as demais disseram que sim. Uma professora citou um curso de formação fornecido pelo CEFAPRO $^{13}$ e outra mencionou cursos online, mas não especificaram o objetivo principal dos cursos.

Atualmente, há uma diversidade de plataformas digitais com ofertas de cursos online que possibilitam a formação continuada na modalidade a distância, nos diversos

${ }^{13}$ Centro de Formação dos Profissionais da Educação do Estado de Mato Grosso. 
campos profissionais. Entretanto, ainda há muitas limitações por parte das políticas públicas educacionais, no que tange à formação docente.

Para Nóvoa (1992), a mudança educacional depende dos professores, sua formação, e da transformação das práticas pedagógicas na sala de aula. Na perspectiva do autor, a formação de professores associa-se a um investimento educativo dos projetos de escola: "Para a formação de professores, o desafio consiste em conceber a escola como um ambiente educativo, onde trabalhar e formar não sejam atividades distintas" (McBride, 1989, apud Nóvoa, 1992, p. 18).

Para que se efetivem essas mudanças, é preciso direcionar um olhar mais atento aos profissionais docentes e sua formação, para que consigam atender à diversidade da demanda atual, composta por estudantes que trazem para o ambiente escolar aparatos tecnológicos que já fazem parte da rotina deles, e não podem ser negligenciados. Além disso, a escola tem o desafio de direcionar o excesso de informação disponível nas mídias digitais e disputar espaço e atenção com as redes sociais e outros recursos. Essa prerrogativa é mais desafiadora quando assumimos a necessidade de que a leitura literária aliada ao uso das tecnologias digitais precisa ser integrada às pautas das políticas de formação na escola.

Com referência à influência das mídias digitais como uma das possibilidades de incentivo à leitura literária, dentre respostas como "pouca" ou "nenhuma", ou que "os alunos continuam desinteressados", algumas respostas merecem destaque:

Professora 1: Se usada de maneira correta, seria ótimo, ainda temos o problema que nem todos os estudantes têm acesso a tecnologia.

Professora 2: A influência é direta e motivadora, tendo em vista que partir de algo que faz parte do cotidiano do educando desperta e cria o sentimento de pertencimento.

Professora 3: As mídias digitais são instrumentos que possibilitam ao professor planejar aulas mais interessantes e atrativas para o aluno, proporcionando um ensino e aprendizado mais eficaz.

Professora 4: As mídias digitais auxiliam no acesso ao conteúdo literário, que algumas vezes não é possível encontrar na biblioteca.

As OC (2012) trazem uma reflexão sobre o leitor contemporâneo, seja professor, seja estudante, e afirmam que esse leitor é construído em boa parte por diversas 
tecnologias que nem mais se surpreendem por sua multifuncionalidade, "pela capacidade de fazer um trânsito direto entre o imaginário e a realidade" (MATO GROSSO, 2012, p. 105).

O documento reconhece duas condições de formação do leitor contemporâneo: por um lado, maior acesso à diversidade de leituras e escritas de gêneros textuais virtuais. Por outro lado, a escola como espaço para promover essas condições, a fim de viabilizar a formação da cidadania.

Assim, as respostas das professoras apontam para a preocupação com as tecnologias presentes no cotidiano dos estudantes. Por mais que as escolas ainda não disponibilizem recursos tecnológicos nem tecnologias digitais suficientes para uso nas práticas docentes, esses meios já estão, de algum modo, nas atividades rotineiras dos estudantes, razão pela qual o acesso a eles e o usufruto dessas ferramentas não podem ser negligenciados no processo de ensino e aprendizagem da leitura literária.

Com referência às maiores dificuldades inerentes à leitura literária na escola, a resposta predominante foi a falta de livros na biblioteca da escola ou que a biblioteca não possuir livros interessantes e compatíveis com a faixa etária dos estudantes. A falta de hábito e de interesse dos alunos foi mencionada por três respondentes e foi usada até a expressão "rejeição" dos alunos por qualquer tipo de leitura. Uma das professoras comentou que o contexto dos clássicos não cativa os adolescentes.

Umas das questões foi acerca dos aplicativos ou programas que as professoras conhecem, utilizam ou poderiam utilizar em sala de aula. As opções mencionadas, além do Youtube ${ }^{14}$ e E-books (livros eletrônicos), foram leitor de textos, revistas eletrônicas, artigos, Kindle ${ }^{15}$ e duas disseram que desconhecem.

A quinta competência ${ }^{16}$ geral da BNCC propõe que, na Educação Básica, o aluno desenvolva as seguintes habilidades:

Compreender, utilizar e criar tecnologias digitais de informação e comunicação de forma crítica, significativa, reflexiva e ética nas diversas práticas sociais (incluindo as escolares) para se comunicar, acessar e disseminar informações, produzir conhecimentos, resolver problemas e exercer protagonismo e autoria na vida pessoal e coletiva. (BRASIL, 2017, p. 8).

\footnotetext{
${ }^{14}$ Site de compartilhamento de vídeos enviados pelos usuários através da Internet.

${ }^{15}$ Leitor de livros digitais.

${ }^{16} \mathrm{Na}$ BNCC, competência é definida como a mobilização de conhecimentos (conceitos e procedimentos), habilidades (práticas, cognitivas e socioemocionais), atitudes e valores para resolver demandas complexas da vida cotidiana, do pleno exercício da cidadania e do mundo do trabalho.
} 
Em consideração ao que preconizam as diretrizes orientativas da BNCC, há uma necessidade de abrir espaço em sala de aula às novas tecnologias, mas não somente como objetos ou ferramentas de ensino, mas com a finalidade de serem empregadas pedagogicamente para darem voz aos estudantes, a fim de que eles sejam protagonistas em sua trajetória escolar. Assim, torna-se possível "fortalecer a autonomia desses adolescentes, oferecendo-lhes condições e ferramentas para acessar e interagir criticamente com diferentes conhecimentos e fontes de informação" (BRASIL, 2017, p. $58)$.

\section{Considerações finais}

Com base no conjunto de dados da pesquisa, foi possível observar que ainda existe a concepção de ensino de literatura limitado à leitura de livros impressos, ou seja, por mais que a escola já disponibilize recursos e tecnologias acessíveis aos estudantes e professores, seu uso não é predominante ou considerado relevante. No entanto, entre a maior parte das respondentes, há uma percepção das tecnologias como aliadas da leitura literária, desde que utilizadas de modo consciente e situado ao contexto de aprendizagem.

Questões referentes à formação inicial e continuada dos docentes, ausência ou precariedade de recursos disponíveis nas unidades escolares, jornada de trabalho são fatores que interferem diretamente na atuação docente e refletem no processo de ensino e aprendizagem. Além disso, sabemos que as inovações tecnológicas caminham a uma velocidade não acompanhada por todas as escolas.

Assim, é importante repensar as práticas pedagógicas voltadas ao ensino de leitura literária, para que se possam aproveitar os recursos e aplicativos disponíveis em favor de um ambiente de estudo que se apresente mais atrativo e motivador aos estudantes, resultando em uma aprendizagem mais contextualizada e significativa.

\section{Referências}

COSCARELLI, Carla Viana, RIBEIRO, Ana Elisa (Orgs.) Letramento digital: aspectos sociais e possibilidades pedagógicas. 3 ed. Belo Horizonte: Ceale; Autêntica, 2011.

COSSON, Rildo. Letramento literário: teoria e prática. São Paulo: Contexto, 2012.

GIL, Antonio Carlos. Métodos e técnicas de pesquisa social. 6. ed. São Paulo: Atlas, 2008. 
LAJOLO, Marisa. Literatura: leitores e leitura. São Paulo: Moderna, 2001.

MATO GROSSO. Secretaria de Estado da Educação. Orientações Curriculares: Área de Linguagens: Educação Básica. Cuiabá: Gráfica Print, 2012.

SANTAELLA, Lúcia. Linguagens líquidas na era da mobilidade. São Paulo: Paulus, 2007.

\section{Outras fontes}

BRASIL. Base Nacional Comum Curricular (BNCC). Educação é a Base. Brasília, MEC/CONSED/UNDIME, 2017. Disponível em: $<$ http://basenacionalcomum.mec.gov.br/wpcontent/uploads/2018/06/BNCC_EI_EF_110518_versaofinal_site.pdf> . Acesso em: 03 dez. 2018.

NÓVOA, António. (Coord.). Formação de professores e profissão docente. In:

Os professores e a sua formação. Lisboa: Dom Quixote, 1992. ISBN 972-20-1008-5. p. 13-33. Disponível em: 〈http://hdl.handle.net/10451/4758> Acesso em: 01 dez. 2018. 